\title{
The state of plant biodiversity in the high plains of Oran (case of the Wilaya of Saida)
}

\author{
Zohra Arabi $^{1 *}$, Khalladi Mederbal ${ }^{2}$, Zohra Benaouf ${ }^{1}$ \\ ${ }^{I}$ Faculty of Natural Sciences and Life.University of Sciences and Technology Houari Boumediene; Algiers; Algeria \\ ${ }^{2}$ Faculty of Natural Sciences and Life, Ibn Khaldoun University Tiaret, Algeria \\ *Corresponding author E-mail: zohra-zouzou@voila.fr
}

Copyright $\odot 2014$ Zohra Arabi et al. This is an open access article distributed under the Creative Commons Attribution License, which permits unrestricted use, distribution, and reproduction in any medium, provided the original work is properly cited.

\begin{abstract}
The wilaya of Saida is experiencing an alarming degradation of ecosystems resulting in the degradation of plant cover, alteration of soil quality and erosion of plant biodiversity. This alarming situation has its origins in various problems such as: human actions, climate change and the lack of an environmental policy.

Our study was conducted on the development of a methodology for multidisciplinary mapping combine's phytoecological between diagnosis and application of remote sensing and Geographic Information Systems G.I.S For an inventory and characterization of the actual state of the plant biodiversity of the region.

The exploitation of satellite data from the Landsat satellites, combined with field studies through systematic sampling, allowed us to map vegetation and a map of plant communities.
\end{abstract}

Keywords: G.I.S, Plant Biodiversity, Phytoecological Diagnosis, Remote Sensing, Saida.

\section{Introduction}

Currently, the whole issue of degradation of forest ecosystems in the final turns on the concept of sustainable development spaces or more precisely implement a controlled and designed to provide eco-efficient wealth management planning forest at various horizons (short, medium and long term) for the future ecological and socioeconomic environment.

The land management in Algeria remains subject to political considerations before being technical. The planning was done through various governments and ministries with concepts and guidelines are subject to discussion. In the absence of a clear policy and long-term based on a manageable regionalization it is difficult to talk about development. It should have been clear a comprehensive approach to a strategy based on ecological, geographical and landscape aspects. The territory's economy is a concept relevant in our country when it dates back to 1975 in other countries. Rational reconquest of the territory remains a major concern of our leaders without defining the elementary bases. This also implies a knowledge and mastery of the operation and interaction of spaces and the natural environment or disturbed [1].

Erosion, prolonged drought, anthropic action and repeated burning are the most destructive factors that lead to degradation the disappearance of forests and the abrupt appearance of matorrals. This situation creates harmful hazards of public health, ecosystems, the living environment and the economy.

The main objective of this study is to combine remote sensing data with field data for the identification and mapping of forest vegetation. The high resolution data like Landsat of 2011, used to create a geo-referenced database on the forest of the province is facing a decline. In this sense, Pouchin [2] notes that, the images are descriptive and they provide much more important visual information compared to man.

Failures recorded in decades in forest management, evidenced by the total lack of forest management policy. Why a map of major technical orientations and future prospects will be drawn at the end of this work in order to implement a coherent forest management plan. 


\section{Experimental design}

\subsection{Materials and methods}

\subsubsection{The study area}

The study area encompasses the thirteen state forests that make up the wilaya of Saida, being located over an area of 174,361 hectares either a $26.17 \%$ of the total area. The vegetation of the forest is composed of: Pinus halpensis (54740 hectares), Quercus ilex (46920 hectares), Tetraclinis articulata (15.640 hectares).

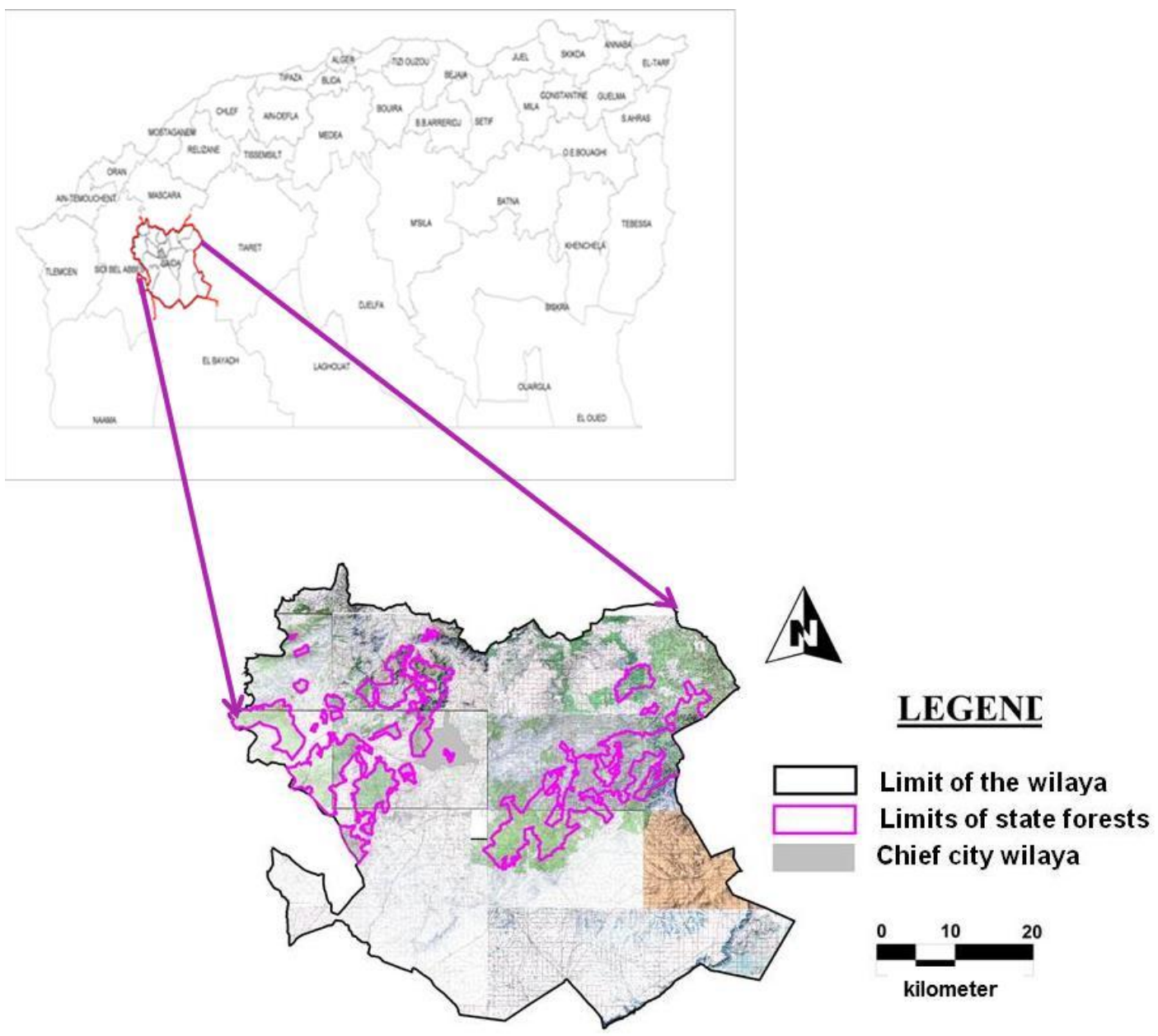

Fig. 1: Limit of the Study Area (States Forests of Wilaya of Saida).

\subsubsection{Climate}

The exploitation of climate data for the period 1970-2010 compared to that of Seltzer [3] , could be found that precipitation experienced an average significant drop of around $85 \mathrm{~mm}$ and temperatures increase $0.5{ }^{\circ} \mathrm{C}$, the consequences on plants are certain.

The climate of the province of Saida is semi-arid to cool winters, it is a major factor affecting forest ecosystems by:

- Irregular rainfall of about $327 \mathrm{~mm} /$ year.

- A high evapotranspiration and a remarkable gap between the rainy periods and dry periods.

- A relatively dry season long over six months from May to October.

\subsubsection{Orography}

The study area is characterized by its very diverse topographic and orographic position. The slope map identifies four classes in order to characterize the relief and set a cut that will eventually help us to provide a relevant management plan. The distribution of these classes is given in slope map below. 


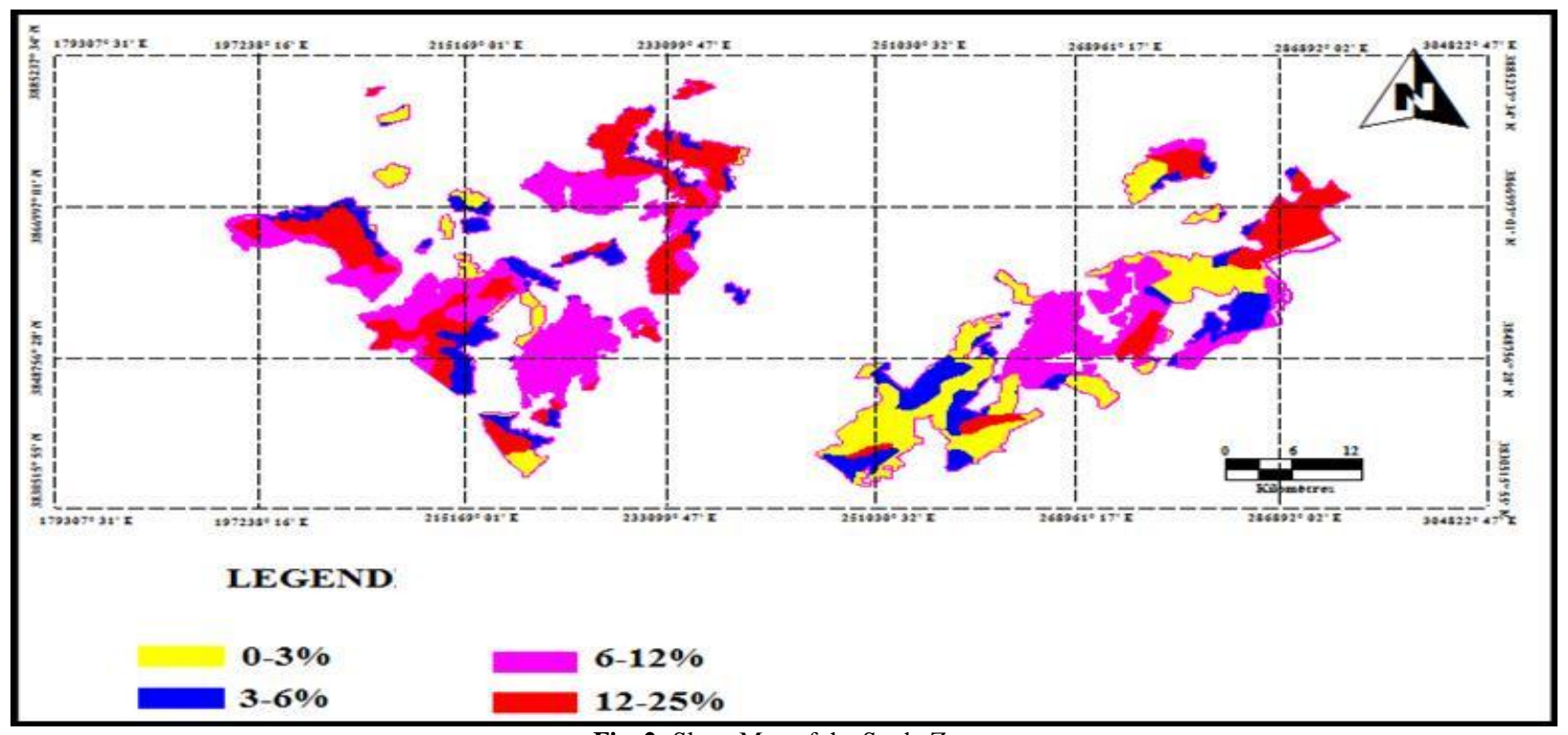

Fig. 2: Slope Map of the Study Zone.

\subsubsection{Methodology}

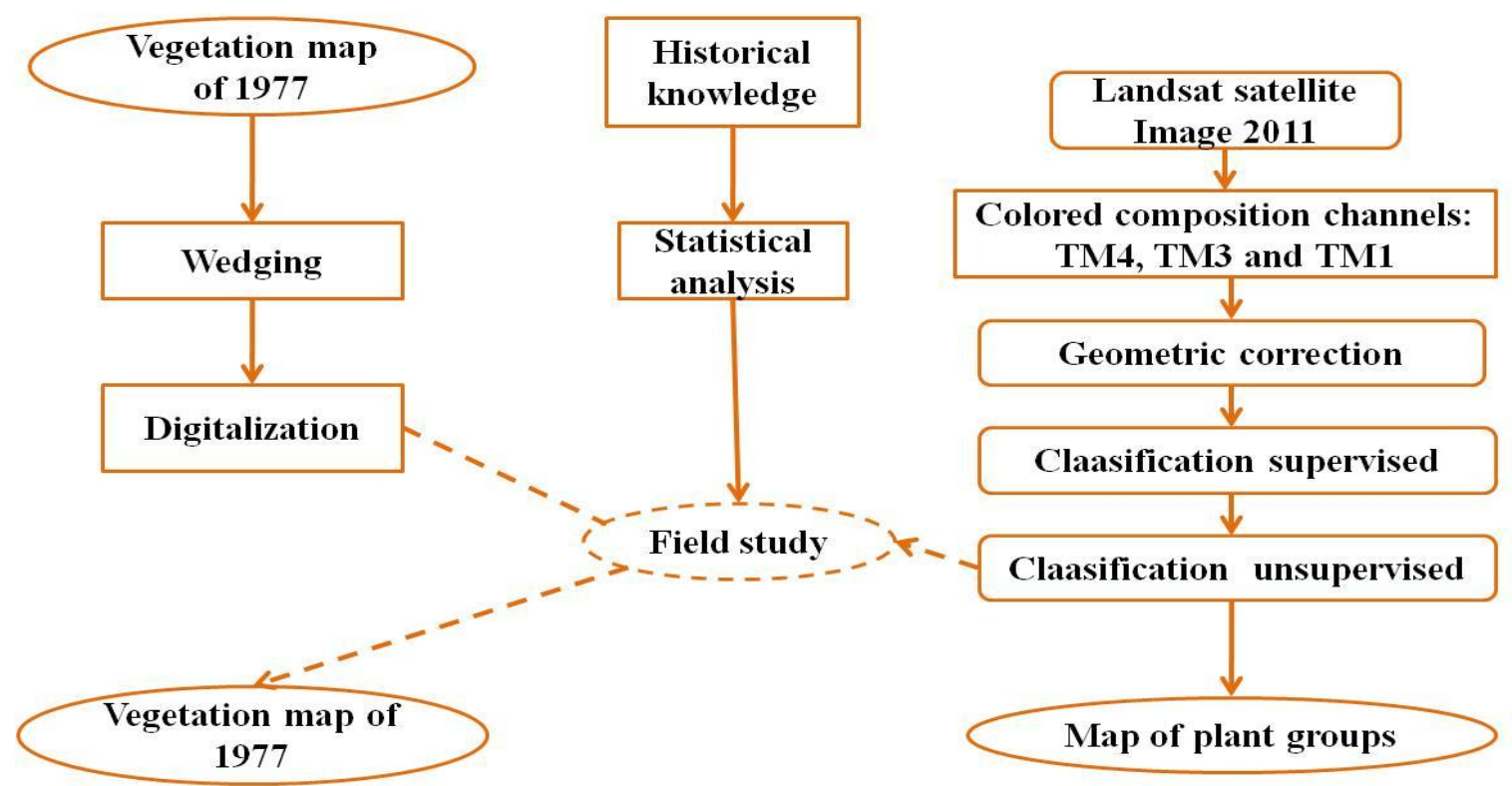

Fig. 3: Flow Chart Showing All the Steps of the Study.

\subsubsection{Sampling}

The study is made from LANDSAT data in the region of Saida of 2011. Its spatial resolution is 30 meters. The maps of Staff (36 cards) of all coverage of the wilaya to scale (1/50000) are used for selecting sampling points raised one hand and the geometric correction the satellite image on the other. Data from IFN (National Forest Inventory) were used as a support for our study. The ground control also lets you update the data.

Each statement was injected on the satellite image. For each type of stand to be inventoried, was conducted by sampling: plots for 4 ha for a dense forest stand and plots of 10 ha for a stand of medium density. The identification of plant species was made by the new Algeria plant established by Quezel and Santa [4].

\subsubsection{Classification and colored composition}

The colored composition was made by the superposition of three channels near infrared, red and green of the LANDSAT image with the assignment of the three primary colors red, green and blue respective order. These channels are selected as best suited for the development of a requested class [5]. 


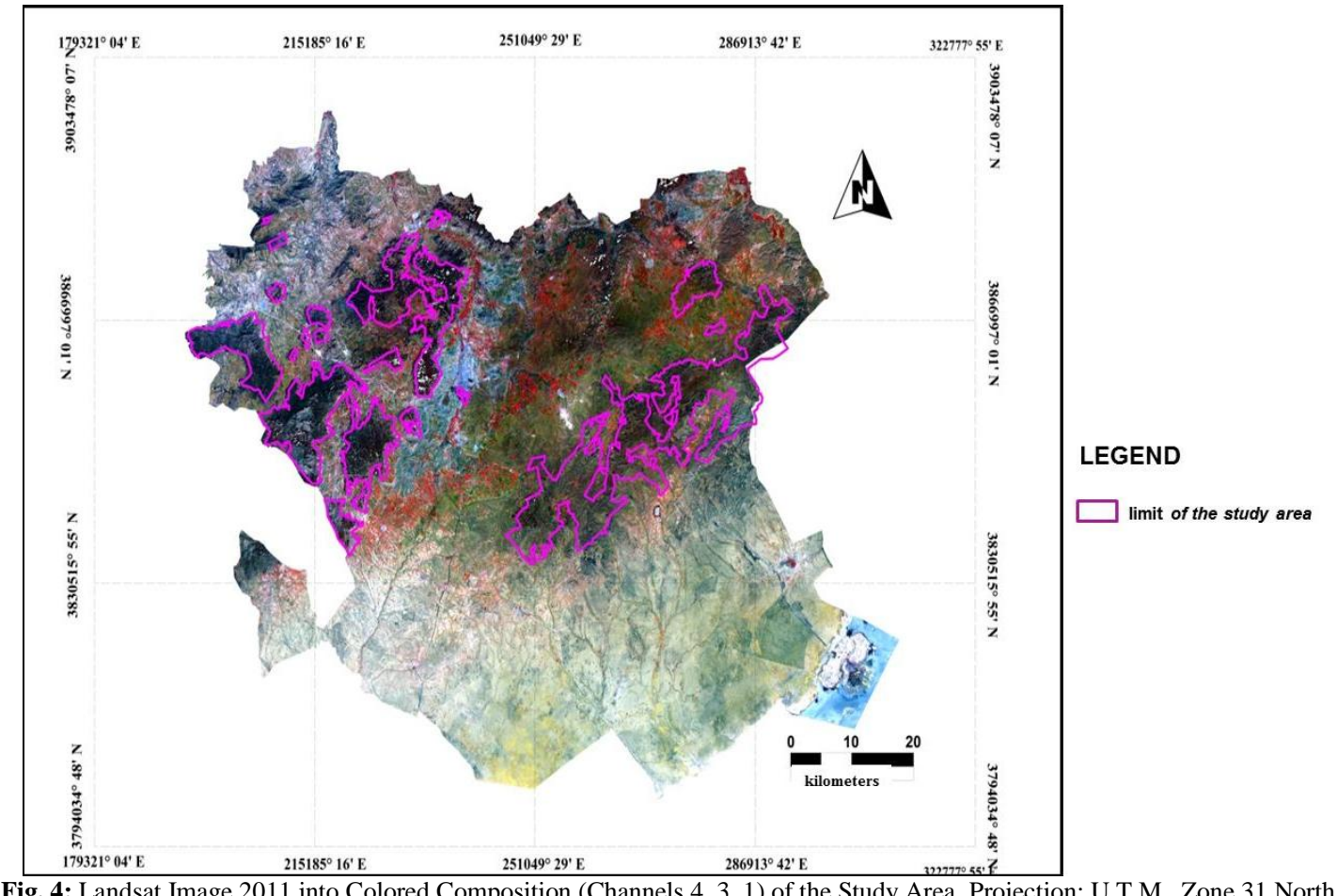

The classification of the image was performed in two phases: unsupervised classification and supervised classification phase. Unsupervised classification was made with the ISODATA algorithm implemented in ENVI 4.7. It helps to have a first representation of vegetation. Supervised classification has been attached to a number of six classes. Based on the work of Andréfouët [6] spatial resolution and error locating a pixel limit the size of objects that can be identified in the image. Indeed, object recognition in the field must be located perfectly on the images in order to define their spectral trace. It is from these spectral traces that builds the classification for construction homogeneous areas. So any negligence level of the object location causes errors in the homogenization of the space studied.

\section{Results}

The study undertaken in the study area shows that all formations ligneous (forests) are subject to a significant decline in the order of $35 \%$ over a period of 45 years (if we superimpose the map obtained the one developed in 1977 [7]. This decline was accompanied by a strong showing of clear and dense scrub. This can be explained to a large extent by a strong disturbance in these fragile ecosystems. This justified worrying situation pulls its roots in several disturbance factors such as land clearing, fires, illegal felling and soil erosion.

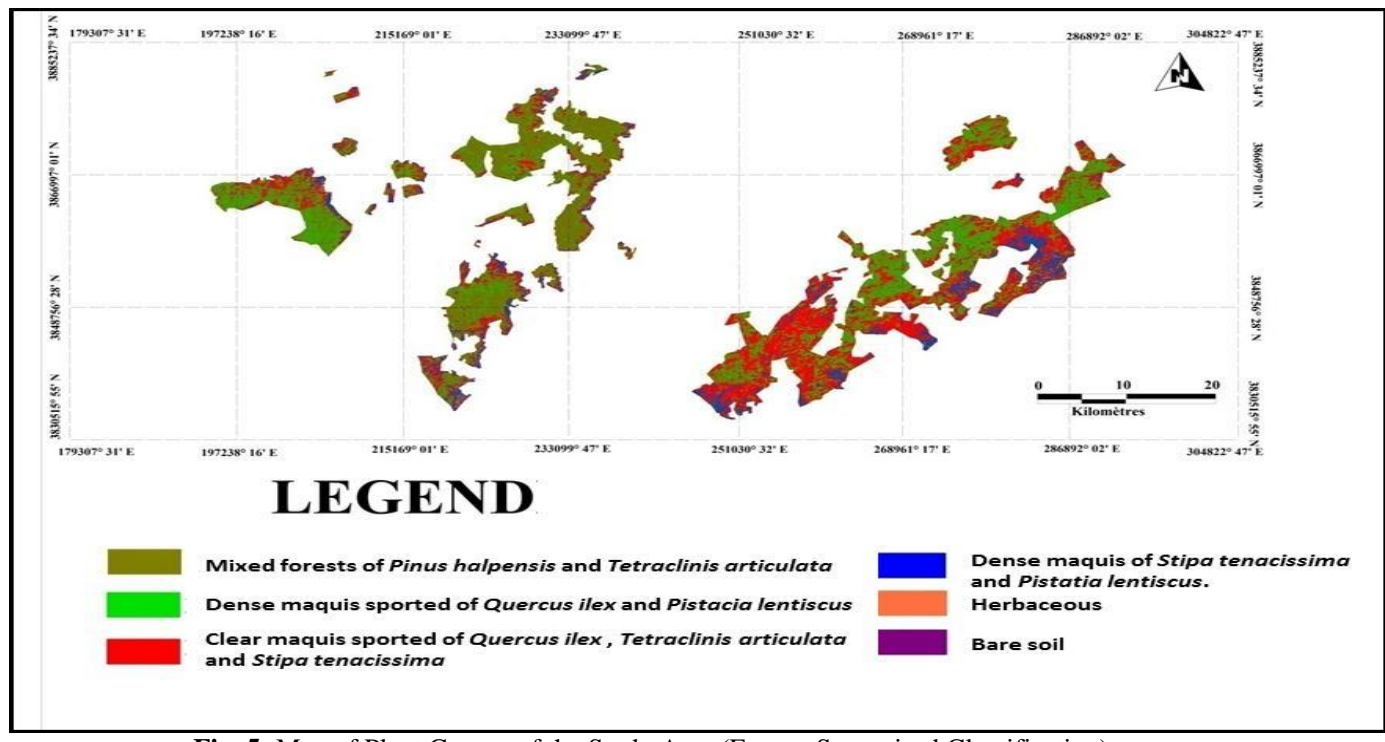

Fig. 5: Map of Plant Groups of the Study Area (From a Supervised Classification). 


\section{Vegetation map}

These are the structures and composition dominant species which are identified on the map.

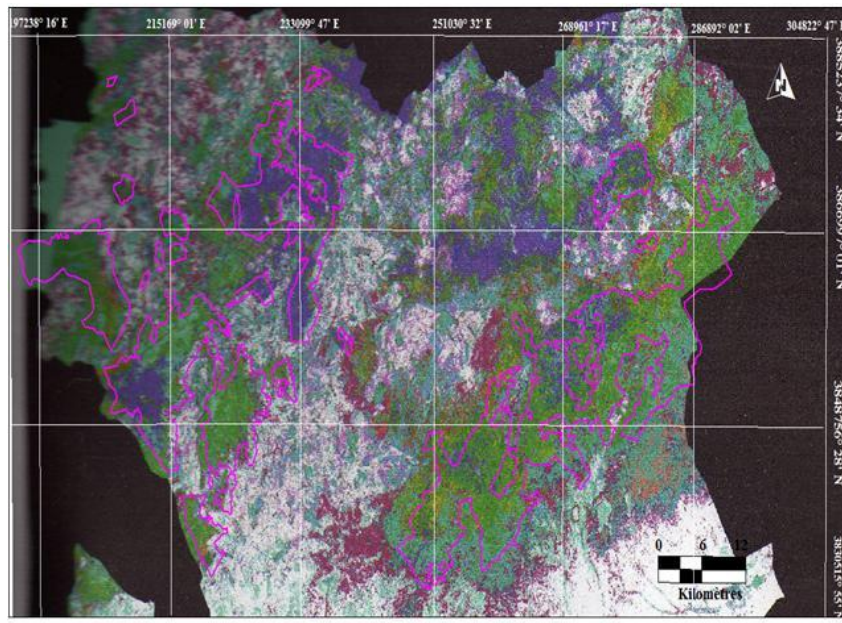

LEGEND

Fig. 6: vegetation map of the study zone.

The results only confirm the state of degradation of the forest ecosystems previously weakened. The main physiognomic units defined in the study area are summarized in the table below:

Table 1: Main Physiognomic Units Defined in the Study Area

\begin{tabular}{|c|c|c|}
\hline Physiognomic units & Description & Percentage [\%] \\
\hline Forest & $\begin{array}{l}\text { Populating of Pinus halpensis } \\
\text { Populating of Pinus halpensis and Tetraclinis articulata } \\
\text { Populating of Quercus ilex } \\
\text { Mixed: Pinus halpensis and Tetraclinis articulata } \\
\text { Populating of Pinus halpensis and Quercus ilex } \\
\text { Populating of Pinus halpensis Quercus ilex and Tetraclinis articulata }\end{array}$ & 25 \\
\hline Maquis & $\begin{array}{l}\text { Dense maquis sported of Quercus ilex and Pistacia lentiscus } \\
\text { Clear maquis sported of Quercus ilex, Juniperus oxycèdrus and Stipa tenacissima } \\
\text { Dense maquis of Stipa tenacissima and Pistacia lentiscus }\end{array}$ & 57 \\
\hline Herbaceous & $\begin{array}{l}\text { Stipa tenacissima } \\
\text { Ampelodesma mauritanica }\end{array}$ & 5 \\
\hline Bare soil & Vegetation with very low recovery rate & 3 \\
\hline
\end{tabular}

\section{Solutions}

In order to make a division into homogeneous areas of the study area, to create parcels management of geometric type that relies on the tracks and sliced firewall. The parcel is a portion of the substantially homogeneous forest seen from the point of soil, climate and population. The area of the plot is based on the species and varies between 10 and $50 \mathrm{Ha}$. Develop a forest is decode what we want to do, given what we can do and deducing what one there must do a summary of the vast development concept [8].

Grim [9] declared in this context, that the development of wooded massifs began to appear in the concerns of the Algerian Forest Service the beginning of the 1970, national and foreign foresters have had to contribute to the development of planned areas wild Algerians are constantly faced with the same problem: the absence of an applicable planning method devoid of a network of basic service with forests and considerable heterogeneity stands. He [9] also added that the proposed semi-arid forest areas management methods were incompatible with the terrain reality. Indeed these developments invariably presented more homogeneous than they actually are forests.

"The forests of Tendfelt, Djaafra and Fenouane are most important, their impact on other areas and the vocation of the wilaya is present and cannot be ignored in any development or overall direction of development approach, its impact on other areas [10].

\section{Conclusion}

Analysis of data from LANDSAT accompanied with field studies used to clearly identify the problems of degradation of forests in national forests in the wilaya of Saida. This helped to map the distribution of different biogeographic plant communities found in the study area through a supervised classification of Landsat satellite image 2011. 
Supervised classification map shows that $57 \%$ of the area of the study area consists of matorral face of a reduced of the forest of around $25 \%$ area, these matorrals replaced forests. The vegetation map of the study area provides an overview on the most dominant species and their distribution in the territory of the wilaya. This allows defining the existing relationship between soil-vegetation-geological substrate and climate.

Faced with this worrying situation, we must sound the alarm immediately to support this major problem with a set of extreme emergency measures. All actions to support must be based on the particularity of each plant community. It is wise to advocate action to protection, production and social use.

Finally, our study is only a preliminary work that remains to be completed. Note that it is never too late to do, just be aware of the seriousness of the problem of forest degradation and their impacts on the ecosystem, the living environment and the economy in order take corrective decisions before it is too late to react and integrate remote sensing and G.I.S considered best tools to help decision-making in environment and ecology.

\section{Acknowledgements}

Authors are grateful to colleagues at the Laboratory for Laboratory of Plant Ecology at the University of Sciences and Technology Houari Boumediene in Bab Ezzouar, Algiers.

\section{References}

[1] Benabdeli K. Quelques réflexions sur la stratégie de gestion durable de la biodiversité dans le bassin méditerranéen: rôle de l'identification de seuils de perturbation acceptables des écosystèmes. [Some Thoughts on the Strategy on the sustainable management of biodiversity in the Mediterranean Basin: the role of the identification of thresholds of acceptable ecosystem disruption.]. International Colloquium on the Conservation and Management of Mainland biodiversity in the Mediterranean Rim. University of Tlemcen 11, 12 and 13 October 2013.

[2] Pouchin T. Elaboration d'un observatoire paysager, Application à l'estuaire de Seine. Thèse de Doctorat [Developing a landscaped observatory Application to the Seine estuary]. Interdisciplinary Center for Transportation Research and International Affairs, Le Havre, PhD Thesis, 2001, $316 \mathrm{p}$.

[3] Seltzer, P. Le climat de l'Algérie, [The climate of the Algeria]. Institute of Weatherfinder. And phys. The globe of the Univer. From Algiers, 1946, 219P, and a color map H.T.

[4] Quezel P. and Santa S. Nouvelle flore de l'Algérie ET des régions désertiques méridionales. [New flora of Algeria and the southern desert regions]. C.N.R.S. Paris. 2 vol. 1962, 1170p.

[5] Douette, M. Etude de la caractérisation de la dynamique des paysages à l'échelle régionale. [Study characterizes landscape dynamics at the regional scale]. Mem Ing of Agronomy .2001; 177 p.

[6] Andrefouët S.J.; Maritorena S. ET Loubersac L. UN bilan de la télédétection appliquée aux milieux coralliens. [An assessment of remote sensing of coral environments].Océanis, vol. 26, no 3, 2002, pp.311-349.

[7] C.R.B.T, Centre de recherche sur les ressources biologiques terrestres; Carte de la végétation de la wilaya de Saida.[ Vegetation map of Saida], 1977.

[8] Jacquiot, M. La forêt. [The forest]. Edition Masson publishers. 1970, 157 pages

[9] Grim, S. Le pré aménagement forestier. [Pre forest management]. Min. Hyd. For. Alger. Univ. Cathol. Louvain. Belgium. 1989 pp 1-45.

[10] Terras M. Typologie, cartographie des stations forestières ET modélisations des peuplements forestiers. Cas des massifs forestiers de la wilaya de Saida (Algérie). Thèse de Doctorat Es'Sciences, [Typology, mapping of forest stations and modeling of forest stands. Case of forest massifs in the wilaya of Saida (Algeria)]. Doctoral Thesis Es' Sciences, University of Tlemcen. 2011, 401 p. 